\title{
Tissue sampling for mutation analysis in colorectal cancer: K-ras is homogeneously distributed throughout the tumor tissue
}

\author{
SUSANNE EKELUND $^{1}$, NIKOS PAPADOGIANNAKIS ${ }^{2}$, HANS OLIVECRONA $^{1}$ and ULRIK LINDFORSS ${ }^{3}$ \\ ${ }^{1}$ Karolinska Institutet, Department of Clinical Science and Education, Södersjukhuset, Stockholm South General Hospital; \\ ${ }^{2}$ Department of Pathology Karolinska University Hospital, Huddinge; ${ }^{3}$ Department of Surgery, Södertälje Hospital and \\ Department of Clinical Science, Intervention and Technology, Karolinska University Hospital, Huddinge, Sweden
}

Received June 15, 2010; Accepted September 2, 2010

DOI: $10.3892 /$ or_00001068

\begin{abstract}
Abstact. The prognostic value of gene abnormalities in colorectal cancer is unclear, varies between investigators, and may be unreliable due to tumor heterogeneity. We analyzed tumors completely divided into biopsies to characterize the overall distribution of LOH at 5q, 17p, 18q, K-ras mutations, and methylation of the p16 and MGMT genes. Seventeen tumors (stage II-III) were completely divided into biopsy cubes from which DNA was sequentially analyzed. The results from fragment analysis for $\mathrm{LOH}$ at $5 \mathrm{q}, 17 \mathrm{p}, 18 \mathrm{q}$, TGGE of the K-ras, and MSP for p16 and MGMT genes were used to characterize the occurrence of these aberrations. $\mathrm{LOH}$ at $18 \mathrm{q}, 17 \mathrm{p}$, and $\mathrm{LOH} 5 \mathrm{q}$ were present in 17/17, 15/17, and 15/16 tumors, respectively. p16 and MGMT were methylated in 16/17 and 14/17, respectively. The frequency of these aberrations varied largely between tumors. K-rasmutations, present in 8/17 tumors, were much more consistently distributed in mutated tumor. Methylation of p16 and MGMT and LOH at $18 \mathrm{q}, 17 \mathrm{p}$, and $5 \mathrm{q}$ are present within the tumor mass in a large majority of CRC tumors and are of no or little prognostic value. K-ras mutations appear more homogeneously distributed. This has clinical relevance for biopsing to predict anti-EGFR response.
\end{abstract}

\section{Introduction}

Since the Fearon/Vogelstein model of multistep carcinogenesis was first presented in 1990 (1), new discoveries have continuously increased our insights into the development of colorectal carcinoma (CRC). An increasing number of both genetic and epigenetic changes have been described. The

Correspondence to: Dr Susanne Ekelund, Department of Clinical Science and Education, Södersjukhuset, Karolinska Institutet, Stockholm South General Hospital, 11669 Stockholm, Sweden E-mail: susanne.tumlin-ekelund@ sodersjukhuset.se

Key words: loss of heterozygosity, colorectal neoplasms, chromosome $17 \mathrm{p}$, chromosome 18q, chromosome 5q, K-ras, methylation status, microsatellite instability, prognostic factors original theory has somewhat been remodeled (2) as further knowledge on mutations of specific genes, epigenetic modulation of tumor suppressors and oncogenes, and allelic imbalance has been explored. Currently, the development of non-inherited CRC is broken down into three distinct tracts of genomic instability governing tumor development. These pathways, consisting of chromosomal instability (CIN), microsatellite instability (MSI) and $\mathrm{CpG}$ island methylator phenotype (CIMP) probably overlap to a large extent (2). As of yet, none of these discoveries specifically has had any major implementation on clinical work.

Curative treatment of CRC is based on careful surgical removal of all tumor-bearing tissue. In addition, today it is generally accepted that adjuvant chemotherapy and (for rectal carcinomas) preoperative radiotherapy improves survival in advanced tumor stages $(3,4)$. The basis for the utilization of adjuvant therapies in addition to surgery, and the intensity of follow-up programs, still depend on histology and the Dukes and TNM classifications. This undoubtfully leads to some degree of over-treatment of patients in advanced stages $(5,6)$ and, reciprocally, omission of a number of patients in earlier stages that may benefit from adjuvant chemotherapy (7).

Accordingly, many attempts have been made to subclassify CRC further, and a range of intratumoral genetic and chromosomal abnormalities have been evaluated with this purpose (2,8-13). In CRC, the presence or not of loss of heterozygosity ( $\mathrm{LOH})$ at different chromosomes (14-19) as well as mutations in, for example, the p53 and K-ras genes (20-24) as well as methylational status (25) have been investigated in relation to prognosis. However, despite a large number of studies of putative genetic markers of relevance for the outcome after surgery, conflicting results are at hand. For instance, differential conclusions of the prognostic significance of K-ras mutations and of $\mathrm{LOH}$ at chromosome $18 \mathrm{q}$ have been presented $(11,14-16,26,27)$ despite similar methods and study material. In addition, and explaining different conclusions, the frequency of a given aberration varies relatively widely between investigators.

We, and others, previously described that the presence or not of $\mathrm{LOH} 18 \mathrm{q}$ and $17 \mathrm{p}$ in different invasive areas of the same colorectal tumors varies in a random fashion (28-30). Thus, single biopsies, which are almost exclusively used in this type of studies, do not guarantee the true status of genetic aberrations in a given tumor, even if the specimen 
Table I. LOH at 5q, 17p, and 18q in the 17 colorectal tumors (number of abnormal biopsies/total number of analyzed biopsies).

\begin{tabular}{|c|c|c|c|c|c|c|}
\hline \multirow[b]{2}{*}{ Patient no. } & \multicolumn{2}{|c|}{ LOH $18 \mathrm{q}$} & \multicolumn{2}{|c|}{ LOH $17 p$} & \multicolumn{2}{|c|}{ LOH $5 q$} \\
\hline & D18S58 & D18S67 & D17S796 & D17S1832 & D5S299 & D5S495 \\
\hline 1 & $1 / 36$ & $25 / 36$ & $19 / 37$ & $33 / 37$ & $2 / 40$ & $2 / 40$ \\
\hline 2 & $\mathrm{H}$ & $12 / 25$ & $1 / 40$ & $\mathrm{H}$ & $6 / 10$ & ND \\
\hline 3 & $2 / 24$ & $8 / 26$ & $\mathrm{H}$ & $\mathrm{H}$ & $14 / 28$ & $12 / 20$ \\
\hline 4 & $0 / 23$ & $10 / 23$ & $6 / 10$ & $10 / 18$ & $0 / 40$ & $2 / 40$ \\
\hline 5 & $17 / 40$ & $6 / 39$ & $\mathrm{H}$ & $\mathrm{H}$ & $12 / 40$ & $21 / 40$ \\
\hline 6 & $8 / 20$ & $14 / 20$ & $14 / 20$ & $\mathrm{H}$ & $\mathrm{H}$ & $\mathrm{H}$ \\
\hline 7 & $1 / 42$ & $4 / 42$ & $\mathrm{H}$ & $8 / 19$ & $6 / 20$ & $12 / 20$ \\
\hline 8 & $6 / 18$ & $\mathrm{H}$ & $4 / 18$ & $12 / 18$ & $19 / 38$ & $\mathrm{H}$ \\
\hline 9 & $2 / 34$ & $8 / 34$ & $\mathrm{H}$ & $2 / 48$ & $8 / 35$ & $6 / 35$ \\
\hline 10 & $\mathrm{H}$ & $12 / 20$ & $11 / 20$ & $6 / 20$ & $\mathrm{H}$ & $14 / 20$ \\
\hline 11 & $16 / 19$ & $7 / 17$ & $2 / 38$ & $3 / 38$ & $15 / 19$ & $\mathrm{H}$ \\
\hline 12 & $15 / 18$ & $8 / 18$ & $14 / 18$ & $\mathrm{H}$ & $11 / 17$ & $12 / 18$ \\
\hline 13 & $5 / 18$ & $0 / 18$ & $2 / 38$ & $\mathrm{H}$ & $2 / 18$ & MI \\
\hline 14 & $\mathrm{H}$ & $8 / 19$ & $6 / 20$ & $\mathrm{H}$ & $1 / 20$ & MI \\
\hline 15 & $20 / 20$ & $19 / 19$ & $\mathrm{H}$ & $19 / 19$ & $\mathrm{H}$ & $17 / 19$ \\
\hline 16 & $10 / 18$ & $14 / 18$ & $17 / 20$ & $19 / 20$ & $\mathrm{H}$ & $0 / 19$ \\
\hline 17 & $15 / 20$ & $20 / 20$ & $16 / 20$ & $\mathrm{H}$ & $16 / 20$ & $20 / 20$ \\
\hline Total & $13 / 14$ & $15 / 16$ & $12 / 12$ & 9/9 & $12 / 13$ & $12 / 13$ \\
\hline Both microsatellite & \multicolumn{2}{|c|}{$17 / 17$} & \multicolumn{2}{|c|}{$15 / 15$} & \multicolumn{2}{|c|}{$15 / 16$} \\
\hline
\end{tabular}

We used automated fragment analysis $\left(\mathrm{Gene} \mathrm{Scan}^{\odot}\right)$ with two different microsatellite markers for each chromosome. As seen, $18 \mathrm{q}$ and $17 \mathrm{p}$ were $\mathrm{LOH}$ positive somewhere in $100 \%$ of the eligible tumors; $5 \mathrm{q}$ was positive in 15 of 16 tumors $(94 \%)$. H, homozygotes for the chosen microsatellites; MI, microsatellite instability; ND, not done.

is microdissected, due to intratumoral heterogeneity (31-33). A recent finding exemplifying the importance of this is the utilization of K-ras analysis to predict the responsiveness to anti-epidermal growth factor antibody therapy in patients with metastatic CRC (34).

To evaluate the natural rates of occurrence, and to establish a more correct figure of the frequencies of allelic loss, methylation of genes and point mutations in CRC, 17 colorectal tumors were completely divided into biopsies, which were analyzed consecutively. We chose to analyze LOH 5q, 17p, 18q, methylation of the p16 and MGMT genes and mutations in $\mathrm{K}$-ras, as these aberrations have been widely studied in CRC.

\section{Materials and methods}

Patients, specimens, and DNA extraction. Seventeen patients (9 female, 8 male) with CRC, 37-88 years of age (median 76) were studied. Informed consent was obtained from each patient prior to surgery. The study was approved by the Ethics committee at Karolinska University Hospital, Stockholm. There were 10 patients with stage II and 7 with stage III disease. The material consisted of 4 rectal, 5 left-sided and 8 right-sided colonic tumors.

Staging was carried out according to the UICC TNM classification on the basis of histological and clinical findings.
The specimens were thoroughly examined macroscopically and only a limited part of the tumor mass were excised to maintain adequate microscopical examination, usually 0.5-1.5 g. Stage I tumors were excluded from the study. With the specimens on ice, the whole tumors were divided into $\sim 3$-mm cubes which were snap-frozen separately in liquid nitrogen, and stored in $-70^{\circ} \mathrm{C}$ until analysis. DNA was extracted from the biopsies, and from normal mucosa at least $10 \mathrm{~cm}$ away from the tumor, with Qiagen tissue kit (Qiagen, Hilden, Germany). All samples were analyzed in sets of 6-40 until one or more aberrations were detected; $2 \mu 1$, with the concentration of $25 \mathrm{ng} / \mu 1$, was used for the polymerase chain reaction (PCR).

Microsatellite markers and amplification. Oligonucleotide primers for microsatellite markers from the short arm of chromosome 17 and the long arm of chromosome 5 and 18 were designed on the basis of published sequences (35). The loci tested were D17S1832 (3 cM telomeric to the p53 gene), D17S796 (1 cM telomeric to the p53 gene), D18S58 (7 cM telomeric to the DCC gene), D18S67 (1 cM centromeric to the DCC gene), D5S299 (7 cM telomeric to the APC gene) and D5S495 (6 cM centromeric to the APC gene). Each of the PCR reaction cycles consisted of denaturation for $30 \mathrm{sec}$ at $94^{\circ} \mathrm{C}$ and annealing for $30 \mathrm{sec}$ at $52^{\circ} \mathrm{C}$ for most of the primers except D18S67, 5q299 and $5 \mathrm{q} 495\left(60^{\circ} \mathrm{C}\right)$ and a final extension at $72^{\circ} \mathrm{C}$ for $30 \mathrm{sec}(25$ cycles $)$. 
Table II. Analyses of K-ras and methylation status of the p16 and MGMT genes throughout the tumors.

\begin{tabular}{|c|c|c|c|}
\hline Patient no. & $\begin{array}{l}\text { K-ras- } \\
\text { mutated/ } \\
\text { total }\end{array}$ & $\begin{array}{c}\text { p16 } \\
\text { methylated/ } \\
\text { total }\end{array}$ & $\begin{array}{c}\text { MGMT } \\
\text { methylated/ } \\
\text { total }\end{array}$ \\
\hline 1 & $0 / 25$ & $11 / 25$ & $25 / 25$ \\
\hline 2 & $23 / 23$ & $25 / 25$ & $0 / 25$ \\
\hline 3 & $0 / 27$ & $15 / 19$ & $18 / 20$ \\
\hline 4 & $0 / 20$ & $16 / 20$ & $16 / 20$ \\
\hline 5 & $1 / 20$ & $9 / 20$ & $5 / 20$ \\
\hline 6 & $0 / 33$ & $12 / 19$ & $1 / 19$ \\
\hline 7 & $0 / 22$ & $21 / 21$ & $3 / 21$ \\
\hline 8 & $15 / 17$ & $18 / 19$ & $13 / 18$ \\
\hline 9 & $0 / 23$ & $19 / 19$ & $17 / 19$ \\
\hline 10 & $17 / 17$ & $19 / 19$ & $5 / 19$ \\
\hline 11 & $0 / 27$ & $4 / 20$ & $19 / 20$ \\
\hline 12 & $17 / 18$ & $17 / 17$ & $12 / 13$ \\
\hline 13 & $26 / 26$ & $1 / 19$ & $0 / 19$ \\
\hline 14 & $0 / 20$ & $19 / 20$ & $18 / 20$ \\
\hline 15 & $0 / 30$ & $0 / 20$ & $19 / 20$ \\
\hline 16 & $19 / 19$ & $8 / 20$ & $0 / 20$ \\
\hline 17 & $20 / 20$ & $9 / 20$ & $17 / 20$ \\
\hline Total $^{\mathrm{a}}$ & $8 / 17$ & $16 / 17$ & $14 / 17$ \\
\hline $\begin{array}{l}\text { Mean } \% \pm \\
\text { SD }^{b}\end{array}$ & $40.4 \pm 12.0$ & $65.4 \pm 8.5$ & $57.0 \pm 10.1$ \\
\hline
\end{tabular}

The number of mutated K-ras/methylated samples per total number of analyzes of each tumor is indicated. The mutated or wild-type form of K-ras was homogeneously present in 14/17 cases. In patients 5,8 , and 12 the results of the $\mathrm{K}$-ras analysis were homogeneous to

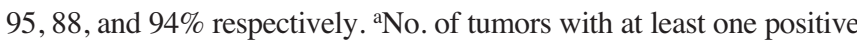
biopsy. ${ }^{b}$ Mean percent positive biopsies/tumor (mean \pm SEM).

Calculation of $\mathrm{LOH}$. $\mathrm{LOH}$ was estimated as described by Cawkwell et al (36) with minor modifications as described (28). After electrophoresis of the PCR products, the fluorescence was detected in a laser scanning region and stored using Gene Scan Collection Software (Applied Biosystems, Foster City, CA). Normal tissue displayed allele ratios between 0.7 and 1.3 for $17 \mathrm{p}$ and $18 \mathrm{q}$, while $5 \mathrm{q}$ rated between 0.8 and 1.4. Values outside these ranges indicated LOH (28).

Temperature gradient gel electrophoresis (TGGE). The amplification of the K-ras gene was performed between codons 9 through 30, thus enabling detection of mutations within codons 12 and 13. TGGE of the purified amplification products was performed in a TGGE system (37) patented by Qiagen and produced by Biometra (Göttingen, Germany). We used horizontal $8 \%$ gels with $4.2 \mathrm{~g}$ urea, $2.0 \mathrm{ml}$ acryl amide (stock solution 37.5:1, 40\%), $0.1 \mathrm{ml}$ TBE (10X), $0.5 \mathrm{ml}$ glycerol (50\%), $22.5 \mu 1$ TEMED and $42 \mu 1$ APS (4\%) in distilled water, filled up to $10 \mathrm{ml}$. An initial perpendicular TGGE made it possible to identify the different alleles by their individual melting behavior yielding the temperature at which the different DNA strands would separate. The screening of the multiple samples was done on plates with pre-fixed slots for 8 or 12 samples by using parallel TGGE.

Methylation-specific PCR (MSP). DNA methylation patterns in $\mathrm{CpG}$ islands of the promotor region of the p16-gene were determined by sodiumbisulfite modification of the unmethylated, but not the methylated, cytosine to uracil, and subsequent PCR using primers specific for either the methylated or the modified unmethylated DNA as described by Herman et al (38). Primer sequences of p16 were for the unmethylated reaction 5'-TTA TTA GAG GGT GGG GTG GAT TGT-3' (sense) and 5'-CAA CCC CAA ACC ACA ACC ATA A-3' (antisense) and for the methylated modified reaction 5'-TTA TTA GAG GGT GGG GCG GAT CGC-3' (sense) and 5'-GAC CCC GAA CCG CGA CCG TAA-3' (antisense). The annealing temperature was $65^{\circ} \mathrm{C}$ for the methylated and $60^{\circ} \mathrm{C}$ for the unmethylated reaction; $35 \mathrm{PCR}$ cycles were carried out. Methylated and unmethylated DNA sequences were detected on $2.5 \%$ agarose gels. Samples giving signals approximately equivalent to the positive methylated control were designated as methylated. Samples giving no signals with positive methylated control, but demonstrating presence of unmethylated DNA, similar to the negative control, were designated as unmethylated.

Statistics. The significance of differences in LOH frequency between K-ras mutated and wild-type tumors were tested using Mann-Whitney U test.

\section{Results}

Loss of heterozygocity and microsatellite instability (MI). $\mathrm{LOH}$ at $18 \mathrm{q}$ was present in all 17 tumors as detected by at least one of the two primers employed. $\mathrm{LOH} \mathrm{17p}$ was undetectable due to homozygosity with both primers in two patients (3 and 5), but positive in all the 15 remaining tumors. $\mathrm{LOH}$ at $5 \mathrm{q}$ was homozygous in one patient (6), and in another patient no loss was seen (16). In all the other 15 patients $\mathrm{LOH} 5 \mathrm{q}$ was present. Clear-cut signs of MSI, revealing multiple fragments on electrophoresis, were seen with one of the primers $(5 q)$ in two patients. Furthermore, in three patients signs of allelic gain (18q) were detected (data not shown).

In patients with only a minor number of samples positive, analyzes were re-run, verifying the results (Table I). As seen, the frequency of biopsies with allelic loss varied widely throughout the individual tumors, ranging between 0 and $100 \%$. Overall, the mean percentage of biopsy samples among the tumors displaying allelic loss ranged from $37.5 \pm 7.8 \%$ (D5S299) to $54.5 \pm 1.2 \%$ (D17S1832). Altogether, counting only tumors possible to analyze with at least one of the primers, 47 of $48(98 \%)$ screenings for $18 \mathrm{q}, 17 \mathrm{p}$, and $5 \mathrm{q}$ were found to harbor $\mathrm{LOH}$ in this material.

Methylation of p16 and MGMT. In one of the tumors none of the biopsies were found to contain methylation of p16 (Table II). The MGMT gene was unmethylated throughout the tumor in three patients. All the other tumors, 16/17 $(94.1 \%)$ for p16 and $14 / 17(82.4 \%)$ for the MGMT gene contained a variable proportion of positive MSP assays. Of the total number of biopsies analyzed, 65.4\% ( \pm ) were 


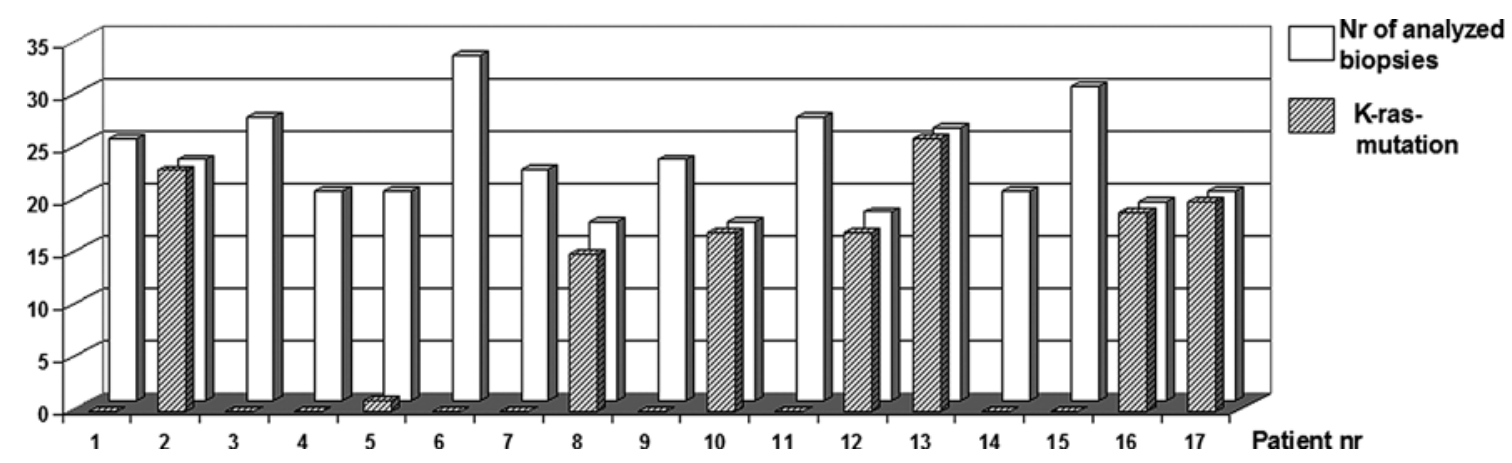

Figure 1. K-ras mutations in the biopsies of the 17 tumors. A clear-cut pattern of distribution is seen: in 10 of the tumors virtually all biopsies, taken throughout the whole tumor mass, contained only wild-type K-ras whereas in 7 tumors practically all biopsies harbored mutations, indicating that K-ras mutation is a very early and thereafter highly conserved aberration in CRC development.

positive for $\mathrm{p} 16$ and $57.0 \%$ for MGMT. There was no correlation between the relative numbers of biopsies with a methylation and the K-ras status or the degree of allelic loss among the tumors; $\mathrm{p}=0.07$ (data not shown). In the two patients displaying MSI (on 5q) in our set of assays (Table I), one had a high degree of methylation and the other tumor did not.

K-ras mutations. K-ras-mutations were found to be distributed in a different pattern (Table II). While the occurance of LOH and methylation positive biopsies seemed randomly distributed throughout the tumors, K-ras in general were homogeneously mutated or not. The mean numbers of analyzed biopsies were 21.6 per tumor, tested in duplicate. In 9/17 tumors only the wild-type K-ras gene was detected. In one tumor, one single biopsy out of 20 harbored a mutation. Of the remaining 7 tumors, 5 were found to homogeneously contain only mutated K-ras; one were mutated in $15 / 17$ biopsies, and one in $17 / 18$. There were no differences between the tumors with/without mutations in correlation to size, histology, localization, or clinical behavior (data not shown). In this limited cohort of patients, a trend towards a higher rate of $\mathrm{LOH}$ in the tumors displaying K-ras mutations was seen; however, this was not significant. In the group of tumors with mutated K-ras, the frequency of biopsies positive for $\mathrm{LOH} 18 \mathrm{q}$ was $55.0 \pm 9.1 \%$ (mean \pm SEM) compared to $33.0 \pm 8.8 \%$ among the wild-type K-ras tumors $(\mathrm{p}=0.24)$. The results for $17 \mathrm{p}$ and $5 \mathrm{q}$ were $44.4 \pm 13.6 \mathrm{vs}$. $40.1 \pm 11.8 \%(p=0.5)$ and $55.6 \pm 12.3 \%$ vs. $29.8 \pm 10.8 \%$ $(\mathrm{p}=0.43)$, respectively.

\section{Discussion}

The results of the present study indicate an important difference in the rates and characteristics of occurrence of point mutations of the K-ras gene in comparison to both allelic imbalances at chromosome 5, 17, and 18 and methylation of the p16 and MGMT genes. Allelic loss and methylation were demonstrated to occur regularly and seemingly mandatory in advanced CRC tumors, while K-ras mutations in approximately half of the tumors occurred in the mutated form and were conserved as the wild-type gene in nine of the seventeen studied cases.
As depicted in Table I, the intratumoral frequency of allelic loss differed widely between the tumors in the present study. In the large number of studies on this issue, a definite variability of reported occurrence rates of $\mathrm{LOH}$ at different chromosomes, and their relative importance for the outcome of CRC, is at hand. The standard methodology involves analysis of very limited areas of the colorectal tumors, using one or a few biopsies $(9,11,13-22,24,26,39-42)$. However, these tumors generally display a morphological mosaiclike pattern, representing different intratumoral subclones of tumor development, ultimately affecting the results of studies of tumor markers as point mutations $(43,44)$, allelic imbalance $(21,45)$, as well as aneuploidy $(11,46,47)$ and methylation status (48). As a rule, histological invasiveness directly affects the results in terms of 'molecular morbidity' (29-31). Since the material investigated is generally extracted from very limited areas of CRC tumors, a considerable variation in the representativeness of tumor biopsies might be expected, even with the use of microdissection. Thus, biopsing for DNA aberrations that are heterogeneously distributed throughout tumors could result in uncertain and even clinically irrelevant data, and might also contribute to the variability in prognostic importance of certain markers found in different studies.

The results also suggest an important difference in the structural occurrence of a specific point mutation, K-ras, and the occurrence of allelic imbalance and methylational status in CRC. While LOH, although present in varying frequencies, seems to be mandatory throughout clinically advanced tumors, reflecting the loss of control mechanisms on a chromosomal level, K-ras mutations are not a prerequisite for the full development to advanced CRC. K-ras mutations, when present, are introduced early in the adenomacarcinoma sequence (1), with a proportion of K-ras mutations in studies of colonic adenomas not differing very much from that of carcinomas $(21,24,39,49,50)$. From our results, with only $3 / 17$ tumors not containing homogeneously mutated or wild-type K-ras (Table II) it may be concluded that this early event is strikingly preserved throughout clonal expansion and tumor progression in CRC.

There were no significant correlation between the occurrence of K-ras mutations and the number of $\mathrm{LOH}$ positive biopsies among the tumors in this study, although 
a trend towards this was seen. The mean follow-up time is only $21(11-43)$ months and the number of patients $(n=17)$ is too small to draw any conclusions on the prognostic effect of K-ras mutations (alone or in addition to allelic losses). In contrast to the case for $\mathrm{LOH}$, however, the present study and earlier results from our group (31) theoretically supports studies of the impact of K-ras status for the outcome of $\mathrm{CRC}$, as mutation in a single biopsy was far more representative for the whole tumor than allelic loss or the methylational status. In the majority of outcome reports, K-ras mutations have had a negative impact on survival and recurrence rates $(20,21,46)$. In addition, our data support the clinical utilization of K-ras analysis from single, or a limited number of biopsies, for individual treatment guidance in clinical practice, and is already in use in decision making for anti-EGF therapy.

In summary, based on analysis of completely divided CRC tumors, our results suggest that chromosomal aberrations and deletions, here represented as LOH $5 \mathrm{q}, 17 \mathrm{p}$, and $18 \mathrm{q}$, and also methylation of MGMT and p16, are unevenly distributed throughout CRC's but practically always present in tumor tissue, or at least abundant in a much higher proportion than generally described. However, K-ras mutations seem to be imprinted early and then preserved throughout the development of sub-clones within the tumor. These findings are of general importance as such for the understanding of clonal expansion within CRC tumors, but also provide a demonstration of the potential pitfalls of genetic determination for clinical utilization. The study clearly supports the use of a single biopsy for the analysis of K-ras as a relevant clinical tool, but also implies careful characterization of other neoplastic genetic events in relation to colorectal 'tumor architecture' and tumor development before they can reach clinical relevance.

\section{Acknowledgements}

We thank Mrs. Lisa Dungner for expert technical assistance. This study was supported by grants from the Swedish Medical Society and the Karolinska Institute.

\section{References}

1. Fearon ER and Vogelstein B: A genetic model for colorectal tumorigenesis. Cell 61: 759-767, 1990.

2. Boland CR and Ricciardiello L: How many mutations does it take to make a tumor? Proc Natl Acad Sci USA 96: 14675-14677, 1999.

3. Dahlberg M, Glimelius B and Pahlman L: Improved survival and reduction in local failure rates after preoperative radiotherapy: evidence for the generalizability of the results of Swedish Rectal Cancer Trial. Ann Surg 229: 493-497, 1999.

4. Moertel CG, Fleming TR, Macdonald JS, et al: Intergroup study of fluorouracil plus levamisole as adjuvant therapy for stage II/Dukes' B2 colon cancer. J Clin Oncol 13: 2936-2943, 1995.

5. Watanabe T, Wu TT, Catalano PJ, et al: Molecular predictors of survival after adjuvant chemotherapy for colon cancer. $\mathrm{N}$ Engl J Med 344: 1196-1206, 2001.

6. Barratt PL, Seymour MT, Stenning SP, et al: DNA markers predicting benefit from adjuvant fluorouracil in patients with colon cancer: a molecular study. Lancet 360: 1381-1391, 2002.

7. Ragnhammar P, Hafstrom L, Nygren P and Glimelius B: A systematic overview of chemotherapy effects in colorectal cancer. Acta Oncol 40: 282-308, 2001.

8. Arends JW: Molecular interactions in the Vogelstein model of colorectal carcinoma. J Pathol 190: 412-416, 2000.
9. Choi SW, Lee KJ, Bae YA, et al: Genetic classification of colorectal cancer based on chromosomal loss and microsatellite instability predicts survival. Clin Cancer Res 8: 2311-2322, 2002.

10. Chung DC: The genetic basis of colorectal cancer: insights into critical pathways of tumorigenesis. Gastroenterology 119: 854-865, 2000

11. Sugai T, Habano W, Nakamura S, et al: Allelic losses of $17 \mathrm{p}$, $5 \mathrm{q}$, and $18 \mathrm{q}$ loci in diploid and aneuploid populations of multiploid colorectal carcinomas. Hum Pathol 31: 925-930, 2000.

12. Laurent-Puig P, Blons H and Cugnenc PH: Sequence of molecular genetic events in colorectal tumorigenesis. Eur J Cancer Prev 8 (Suppl. 1): S39-S47, 1999.

13. Leggett B, Young J, Buttenshaw R, et al: Colorectal carcinomas show frequent allelic loss on the long arm of chromosome 17 with evidence for a specific target region. Br J Cancer 71: 1070-1073, 1995.

14. Ogunbiyi OA, Goodfellow PJ, Herfarth K, et al: Confirmation that chromosome $18 \mathrm{q}$ allelic loss in colon cancer is a prognostic indicator. J Clin Oncol 16: 427-433, 1998.

15. Martinez-Lopez E, Abad A, Font A, et al: Allelic loss on chromosome $18 \mathrm{q}$ as a prognostic marker in stage II colorectal cancer. Gastroenterology 114: 1180-1187, 1998.

16. Jen J, Kim H, Piantadosi S, et al: Allelic loss of chromosome $18 \mathrm{q}$ and prognosis in colorectal cancer. N Engl J Med 331: 213-221, 1994.

17. Takanishi DM Jr, Angriman I, Yaremko ML, Montag A, Westbrook CA and Michelassi F: Chromosome 17p allelic loss in colorectal carcinoma. Clinical significance. Arch Surg 130: 585-589, 1995.

18. Iino H, Fukayama M, Maeda Y, et al: Molecular genetics for clinical management of colorectal carcinoma. 17p, 18q, and 22q loss of heterozygosity and decreased DCC expression are correlated with the metastatic potential. Cancer 73: 1324-1331, 1994.

19. De Angelis PM, Stokke T, Beigi M, Mjaland O and Clausen OP: Prognostic significance of recurrent chromosomal aberrations detected by comparative genomic hybridization in sporadic colorectal cancer. Int J Colorectal Dis 16: 38-45, 2001.

20. Esteller M, Gonzalez S, Risques RA, et al: K-ras and p16 aberrations confer poor prognosis in human colorectal cancer. J Clin Oncol 19: 299-304, 2001

21. Font A, Abad A, Monzo M, et al: Prognostic value of K-ras mutations and allelic imbalance on chromosome $18 \mathrm{q}$ in patients with resected colorectal cancer. Dis Colon Rectum 44: 549-557, 2001.

22. Hirvikoski P, Auvinen A, Servomaa K, et al: K-ras and p53 mutations and overexpressions as prognostic factors in female rectal carcinoma. Anticancer Res 19: 685-691, 1999.

23. Thebo JS, Senagore AJ, Reinhold DS and Stapleton SR: Molecular staging of colorectal cancer: K-ras mutation analysis of lymph nodes upstages Dukes B patients. Dis Colon Rectum 43: $155-162,2000$

24. Fung C, Bragg T, Newland R, et al: K-ras mutation and loss of heterozygosity of chromosome $17 \mathrm{p}$ and survival in colorectal cancer. Aust N Z J Surg 67: 239-244, 1997.

25. Zlobec I and Lugli A: Prognostic and predictive factors in colorectal cancer. J Clin Pathol 61: 561-569, 2008.

26. Reymond MA, Dworak O, Remke S, Hohenberger W, Kirchner T and Kockerling F: DCC protein as a predictor of distant metastases after curative surgery for rectal cancer. Dis Colon Rectum 41: 755-760, 1998.

27. Carethers JM, Hawn MT, Greenson JK, Hitchcock CL and Boland CR: Prognostic significance of allelic lost at chromosome $18 \mathrm{q} 21$ for stage II colorectal cancer. Gastroenterology 114: 1188-1195, 1998.

28. Lindforss U, Fredholm H, Papadogiannakis N, Gad A, Zetterquist $\mathrm{H}$ and Olivecrona $\mathrm{H}$ : Allelic loss is heterogeneous throughout the tumor in colorectal carcinoma. Cancer 88: 2661-2667, 2000.

29. Nagel S, Borisch B, Thein SL, et al: Somatic mutations detected by mini- and microsatellite DNA markers reveal clonal intratumor heterogeneity in gastrointestinal cancers. Cancer Res 55: 2866-2870, 1995.

30. Baisse B, Bouzourene H, Saraga EP, Bosman FT and Benhattar J: Intratumor genetic heterogeneity in advanced human colorectal adenocarcinoma. Int J Cancer 93: 346-352, 2001.

31. Lindforss U, Papadogiannakis N, Zetterquist H, Lindberg G and Olivecrona H: Distribution of genetic variants in preneoplastic areas of colorectal tumours. Eur J Surg Oncol 29: 491-496, 2003. 
32. Boni R, Matt D, Voetmeyer A, Burg G and Zhuang Z: Chromosomal allele loss in primary cutaneous melanoma is heterogeneous and correlates with proliferation. J Invest Dermatol 110: 215-217, 1998 .

33. Boland CR, Sato J, Appelman HD, Bresalier RS and Feinberg AP: Microallelotyping defines the sequence and tempo of allelic losses at tumour suppressor gene loci during colorectal cancer progression. Nat Med 1: 902-909, 1995.

34. Linardou H, Dahabreh IJ, Kanaloupiti D, et al: Assessment of somatic k-RAS mutations as a mechanism associated with resistance to EGFR-targeted agents: a systematic review and meta-analysis of studies in advanced non-small-cell lung cancer and metastatic colorectal cancer. Lancet Oncol 9: 962-972, 2008.

35. Weissenbach J, Gyapay G, Dib C, et al: A second-generation linkage map of the human genome. Nature 359: 794-801, 1992.

36. Cawkwell L, Bell SM, Lewis FA, Dixon MF, Taylor GR and Quirke P: Rapid detection of allele loss in colorectal tumours using microsatellites and fluorescent DNA technology. Br J Cancer 67: 1262-1267, 1993.

37. Wartell RM, Hosseini SH and Moran CP Jr: Detecting base pair substitutions in DNA fragments by temperature-gradient gel electrophoresis. Nucleic Acids Res 18: 2699-2705, 1990.

38. Herman JG, Graff JR, Myohanen S, Nelkin BD and Baylin SB: Methylation-specific PCR: a novel PCR assay for methylation status of CpG islands. Proc Natl Acad Sci USA 93: 9821-9826, 1996.

39. Bouzourene H, Gervaz P, Cerottini JP, et al: p53 and Ki-ras as prognostic factors for Dukes' stage B colorectal cancer. Eur J Cancer 36: 1008-1015, 2000.

40. Chiang JM, Chou YH and Chou TB: K-ras codon 12 mutation determines the polypoid growth of colorectral cancer. Cancer Res 58: 3289-3293, 1998.
41. Jeong SY, Shin KH, Shin JH, et al: Microsatellite instability and mutations in DNA mismatch repair genes in sporadic colorectal cancers. Dis Colon Rectum 46: 1069-1077, 2003.

42. Lawes DA, SenGupta S and Boulos PB: The clinical importance and prognostic implications of microsatellite instability in sporadic cancer. Eur J Surg Oncol 29: 201-212, 2003.

43. Toyooka S, Tsukuda K, Ouchida M, et al: Detection of codon 61 point mutations of the K-ras gene in lung and colorectal cancers by enriched PCR. Oncol Rep 10: 1455-1459, 2003.

44. Forslund A, Kressner U, Lonnroth C, Andersson M, Lindmark G and Lundholm K: P53 mutations in colorectal cancer assessed in both genomic DNA and cDNA as compared to the presence of p53 LOH. Int J Oncol 21: 409-415, 2002.

45. Nowak MA, Komarova NL, Sengupta A, et al: The role of chromosomal instability in tumor initiation. Proc Natl Acad Sci USA 99: 16226-16231, 2002.

46. Bazan V, Migliavacca M, Zanna I, et al: DNA ploidy and S-phase fraction, but not p53 or NM23-H1 expression, predict outcome in colorectal cancer patients. Result of a 5-year prospective study. J Cancer Res Clin Oncol 128: 650-658, 2002.

47. Rajagopalan H, Nowak MA, Vogelstein B and Lengauer C: The significance of unstable chromosomes in colorectal cancer. Nat Rev Cancer 3: 695-701, 2003.

48. Boland CR, Shin SK and Goel A: Promoter methylation in the genesis of gastrointestinal cancer. Yonsei Med J 50: 309-321, 2009.

49. Takayama T, Ohi M, Hayashi T, et al: Analysis of K-ras, APC, and beta-catenin in aberrant crypt foci in sporadic adenoma, cancer, and familial adenomatous polyposis. Gastroenterology 121: 599-611, 2001.

50. Giaretti W, Rapallo A, Sciutto A, et al: Intratumor heterogeneity of k-ras and p53 mutations among human colorectal adenomas containing early cancer. Anal Cell Pathol 21: 49-57, 2000. 